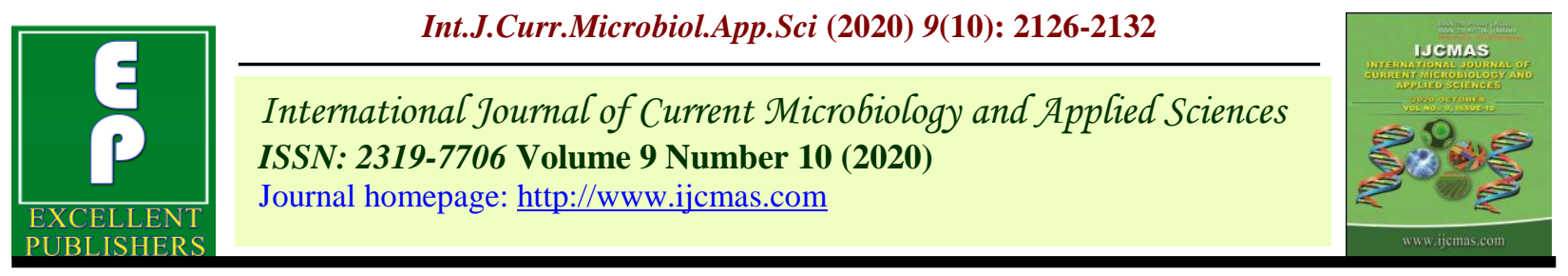

Original Research Article

https://doi.org/10.20546/ijcmas.2020.910.259

\title{
Development of Manually Drawn Engine Powered Fodder Crop Harvester
}

\author{
M. V. Jalu*, V. K. Tiwari and V. S. Vala \\ Department of Farm Machinery and Power Engineering, Collage of Agricultural Engineering \\ and Technology, JAU, Junagadh (Gujarat), India \\ *Corresponding author
}

\section{A B S T R A C T}

Keywords

Fodder crop,

Harvesting,

Mechanization,

Cutting efficiency

Article Info

Accepted:

17 September 2020

Available Online:

10 October 2020
Fodder harvesting is a tedious operation in agriculture field. In India, agriculture is facing serious challenges of scarcity of agricultural labour not only in peak seasons but almost throughout the year. It is very time consuming and stressful operation. A manually drown engine powered fodder crop harvester was developed in the department of FMPE at CAET, JAU, Junagadh. Three different forward speed (0.3-0.6, 0.6-0.9 and 0.9-1.2 $\mathrm{km} / \mathrm{h}$ ) were used for the test performance. The maximum cutting efficiency (96.06 \%), field efficiency $(81.47 \%)$ and minimum plant damage $(7.08 \%)$ were found at speed range of $0.6-0.9 \mathrm{~km} / \mathrm{h}$. The total cost saving of developed fodder crop harvester was found $58.07 \%$ as compare to manual harvesting.

\section{Introduction}

Fodder maize is one of the important fodder crops of India. India is one of the top 10 maize producers in the world; it contributes around $2-3 \%$ of the total maize produced globally from the area of 9.47 Mha and with production of 28.72 MT. From total production of maize around $13 \%$ is used for livestock feed. Gujarat is one of the medium maize productivity states. Traditionally, the harvesting of fodder crop is done manually by sickle, which demands considerable amount of labor, drudgery, time and cost to harvest, which reflects on total production cost of the fodder.
Therefore, a manually drawn engine powered fodder crop harvester to reduce working stress and increase working capacity of a man, was developed and it's performance was evaluated in the department of farm machinery and power engineering at collage of agricultural engineering and technology, JAU, Junagadh.

Amer Eissa et al., (2008), found the shear strength of maize stalks at bottom, middle and top parts of stalks were 8.94, 7.06 and 5.14 MPa respectively. Michael (1978), found that manual harvesting generally involves slicing and tearing action that resulted plant structure failed due to compression, tension or shear. The serrated sickles combine a slicing and 
sawing action in cutting devices restricted the sliding action of the plant on the blade edge and helped to retain the plant on the blade for adequate cutting. It has also been reported that sickle with serrated edge required the resharpening rarely as compared to smooth edge sickle.

Yiljep and Mohammed (2005), found the critical cutting speed for sugarcane was 13.8 to $18.4 \mathrm{~m} / \mathrm{s}$ while, for sorghum, it was between 5.2 to $7.3 \mathrm{~m} / \mathrm{s}$.

Kongre et al., (2016), advised that the carbide metal tip may be used for toughness of cutting mechanism on periphery of cutting disc. They used the blade of stainless-steel having diameter of $150 \mathrm{~mm}$ and number of teeth was 40.

Hosseinzadeh et al., (2009), showed that the shearing stress of wheat stems decreased as the moisture content decreased. The shearing force of stems decreased as the cutting height of stalk increased, because of a reduction in stalk diameter.

Alandkar (2017) used high Carbon steel shearing type circular shape blades with serrated edge. Diameter of each cutting blade was $300 \mathrm{~mm}$, thickness $4 \mathrm{~mm}$ and rpm of cutting blade was 376 .

\section{Materials and Methods}

A manually drawn engine powered fodder crop harvester was developed to harvest fodder maize crop. It cuts the fodder crop at minimum height from ground level and windrows it. The machine has a vertical structure. The machine is pushed manually moves forward easily due to four wheels. It cuts single row at a time. There is a conveying unit to windrow the fodder crop after harvesting. The machine was consisted of main frame, $1.5 \mathrm{hp}-2$ stroke petrol engine, 4-wheels for easy movement, cutting unit, conveying unit and throttle lever. To transmit power to cutting unit and conveying through chain-sprocket and belt-pully mechanism were used.

The most common variety of fodder maize i.e. African tall was taken for the study. During the harvesting the average height, diameter and row to row distance of the plant were 145 $\mathrm{cm}, 2 \mathrm{~cm}$ and $60 \mathrm{~cm}$ respectively. The study was conducted at CAET, JAU, Junagadh, Gujarat. The test plot had medium black soil, levelled surface and moisture content was $21.88 \%$ on dry basis.

\section{Developed fodder crop harvester}

Main frame: The overall dimensions of main frame are $45 \mathrm{~cm} \times 35 \mathrm{~cm} \times 100 \mathrm{~cm}(\mathrm{~L} \times \mathrm{W} \times$ $\mathrm{H})$. It consisted of square bar pipe of galvanized iron.

Power source: A single cylinder 2- stroke petrol engine of $1.5 \mathrm{hp}$ power, was used as a power source.

Cutting blade: For harvesting the fodder crop, saw circular cutting blade of $250 \mathrm{~mm}$ diameter and made of high carbon steel was selected.

Supporting wheel: To move the machine over the field, two solid polyurethane plastic front wheels and two cast iron rear wheels were provided. The front wheels have $18 \mathrm{~cm}$ diameter and $4 \mathrm{~cm}$ in thickness. The diameter and thickness of each rear wheel were $24 \mathrm{~cm}$ and $4 \mathrm{~cm}$ respectively.

Handle: It was fabricated from the galvanized iron pipe having a round cross section with thickness $1 \mathrm{~mm}$. The overall length of the handle was $480 \mathrm{~mm}$.

Gear box: The gear box having aluminium body with gear reduction ratio of 10:1 was used. The output engine shaft which is having 
3600 RPM was directly connected with gear box and maximum output RPM was 360 .

Conveyor unit: The output shaft of gear box was connected with conveying unit through belt pully mechanism. Conveyer belt having 5 $\mathrm{cm}$ width with lugs were attached on it.

Crop guide: To gather all stems of plant, a triangle shape crop guide was used. Crop guide was fabricated form cast iron having square cross section. The length of this guide is $30 \mathrm{~cm}$.

Star wheel: The star wheel was used to convey the harvested crop at one side. Stare wheel helps the conveyor belt to efficiently convey the harvested crop (Fig. 1).

\section{Field testing}

\section{Cutting efficiency}

It is the ratio of the number of harvested stalks (number of stalks before harvesting minus number of unharvested stalks) to number of stalks before harvesting in a $1 \mathrm{~m}^{2}$ area.

Cutting efficiency $=\left(\mathrm{W}_{1}-\mathrm{W}_{2}\right) / \mathrm{W}_{1} \times 100$

Where,

$\mathrm{W}_{1}=$ Number of stalks before harvesting

$\mathrm{W}_{2}=$ Number of Unharvested stalks

\section{Field efficiency}

The term field efficiency is used to describe the efficiency of the machine is in operation. It is the ratio of effective field capacity to the theoretical field capacity and expressed in percentage.

Field efficiency $=($ Effective field capacity $) /$ (Theoretical field capacity) $\times 100$

\section{Plant damage}

After harvesting, a number of observations were taken randomly to measure the damaged stems of the maize. A frame of $1 \mathrm{~m} \times 1 \mathrm{~m}$ was used to count the number of plants clog/crushed/damaged. It was measured at $S_{1}$ $(0.3-0.6 \mathrm{~km} / \mathrm{h}), S_{2}(0.6-0.9 \mathrm{~km} / \mathrm{h})$ and $S_{3}$ $(0.9-1.2 \mathrm{~km} / \mathrm{h})$ speed of the machine.

\section{Statistical analysis}

Statistical analysis was carried out by Complete Randomized Design method in which the effect of various treatments on various parameters were analysed.

\section{Economics}

The cost of fabrication of fodder crop harvester was worked out on the basis of cost of used material, machining cost and the labour cost. This cost was considered as fixed cost. The variable cost was determined by the operational cost of the developed machine.

\section{Performance evaluation}

The performance of the developed machine was evaluated in terms of cutting efficiency, field capacity, field efficiency, plant damage and economics. The results data were analysed statistically and discussed under the following heads.

\section{Cutting efficiency}

Effect of different forward speed on cutting efficiency was found highly significant at $5 \%$ and $1 \%$ level (Table 1). The maximum cutting efficiency i.e. $96.06 \%$ was recorded at $S_{2}$ forward speed. The minimum cutting efficiency i.e. $86.98 \%$ was observed at $\mathrm{S}_{3}$ forward speed, while at $S_{1}$ forward speed it was observed $88.46 \%$. 
The cutting efficiency was plotted against forward speed of machine as shown in Fig. 2. The cutting efficiency increased as forward speed increased from $S_{1}$ to $S_{2}$. But it decreased with further increase of speed from $\mathrm{S}_{2}$ to $\mathrm{S}_{3}$. Increased cutting efficiency with $\mathrm{S}_{2}$ $(10.44 \%)$ followed by $S_{1}(1.71 \%)$ as compared with $\mathrm{S}_{3}$. From figure it is clear that, the maximum cutting efficiency i.e. $96.06 \%$ was observed in the range of the forward speed of $0.6-0.9 \mathrm{~km} / \mathrm{h}$ as compared to other speeds. It might be due to at lower speed $\left(S_{1}\right)$ the disc could not developed sufficient impact and shear force required to get a sharp cut and at higher speed $\left(\mathrm{S}_{3}\right)$ some plants remained uncut. Thus, $S_{2}$ speed is recommended.

Table.1 Effect of forward speed on cutting efficiency

\begin{tabular}{|c|c|}
\hline Treatment & Cutting efficiency (\%) \\
\hline $\mathrm{S}_{1}=0.3-0.6 \mathrm{~km} / \mathrm{h}$ & 88.47 \\
\hline $\mathrm{S}_{2}=0.6-0.9 \mathrm{~km} / \mathrm{h}$ & 96.07 \\
\hline $\mathrm{S}_{3}=0.9-1.2 \mathrm{~km} / \mathrm{h}$ & 86.98 \\
\hline S.Em. \pm & 1.75 \\
\hline C.D. at $5 \%$ & 5.27 \\
\hline CV \% & 4.73 \\
\hline
\end{tabular}

Table.2 Effect of forward speed on field efficiency

\begin{tabular}{|c|c|}
\hline Treatment & Field efficiency $(\boldsymbol{\%})$ \\
\hline $\mathrm{S}_{1}=0.3-0.6 \mathrm{~km} / \mathrm{h}$ & 79.1774 \\
\hline $\mathrm{S}_{2}=0.6-0.9 \mathrm{~km} / \mathrm{h}$ & 81.4749 \\
\hline $\mathrm{S}_{3}=0.9-1.2 \mathrm{~km} / \mathrm{h}$ & 69.8910 \\
\hline S.Em. \pm & 0.703 \\
\hline C.D. at $5 \%$ & 2.1186 \\
\hline CV \% & 2.24 \\
\hline
\end{tabular}

Table.3 Effect of forward speed on plant damage

\begin{tabular}{|c|c|}
\hline Treatment & Plant damage (\%) \\
\hline $\mathrm{S}_{1}=0.3-0.6 \mathrm{~km} / \mathrm{h}$ & 11.49 \\
\hline $\mathrm{S}_{2}=0.6-0.9 \mathrm{~km} / \mathrm{h}$ & 7.077 \\
\hline $\mathrm{S}_{3}=0.9-1.2 \mathrm{~km} / \mathrm{h}$ & 18.00 \\
\hline S.Em. \pm & 0.52 \\
\hline C.D. at $5 \%$ & 1.56 \\
\hline CV \% & 9.5 \\
\hline
\end{tabular}


Table.4 Cost parameters of fodder crop harvester

\begin{tabular}{|c|l|l|}
\hline Sr. No. & Parameters & Values \\
\hline 1 & $\begin{array}{l}\text { Capital cost of the developed fodder crop } \\
\text { harvester }\end{array}$ & $\square 40,000$ \\
\hline 2 & Cost for harvesting operation & $\square 111$ per h \\
\hline 3 & Custom hiring charge & $\square 138$ per h \\
\hline 4 & Payback period & 4 year \\
\hline 5 & Benefit Cost ratio & 2.49 \\
\hline
\end{tabular}

Fig.1 Developed fodder crop harvester
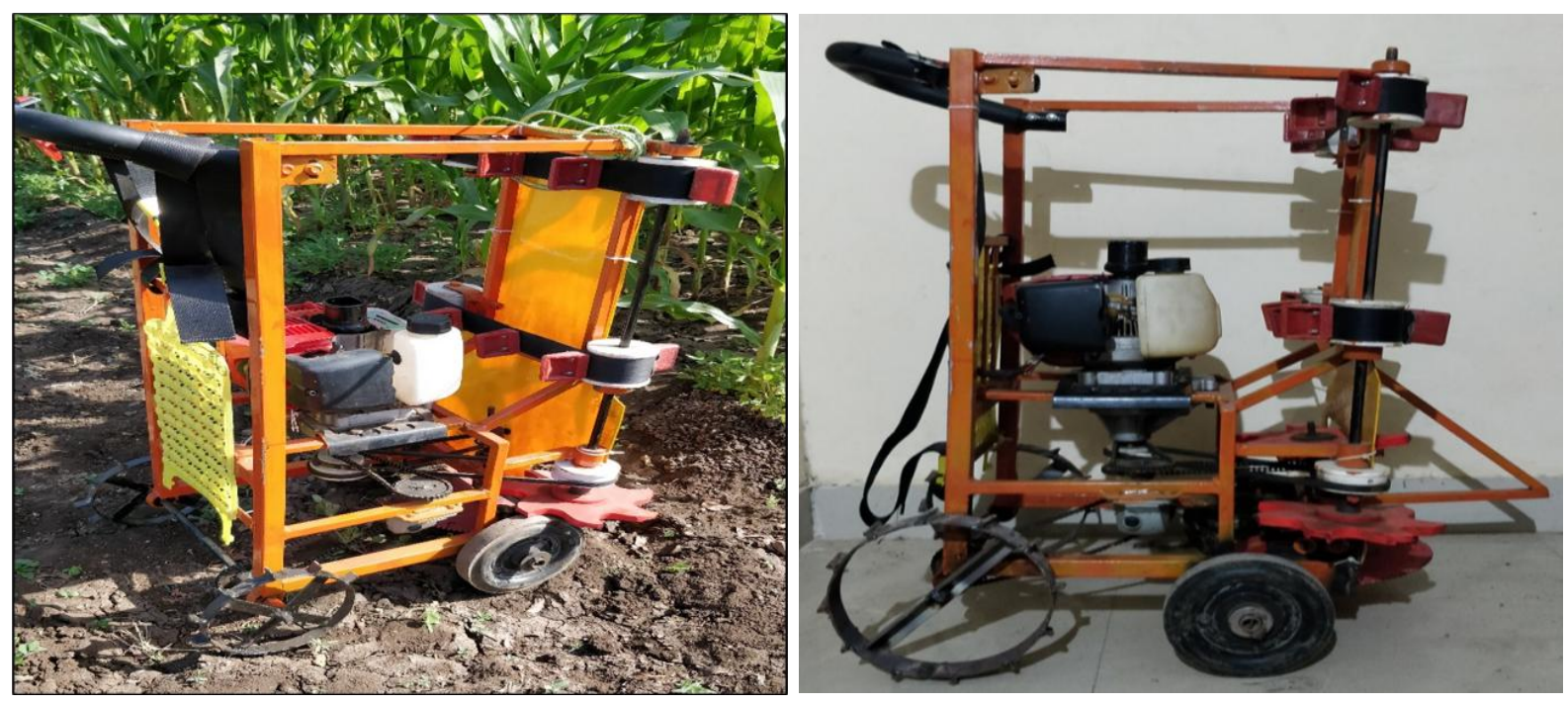

Fig.2 Effect of forward speed of machine on cutting efficiency (\%)

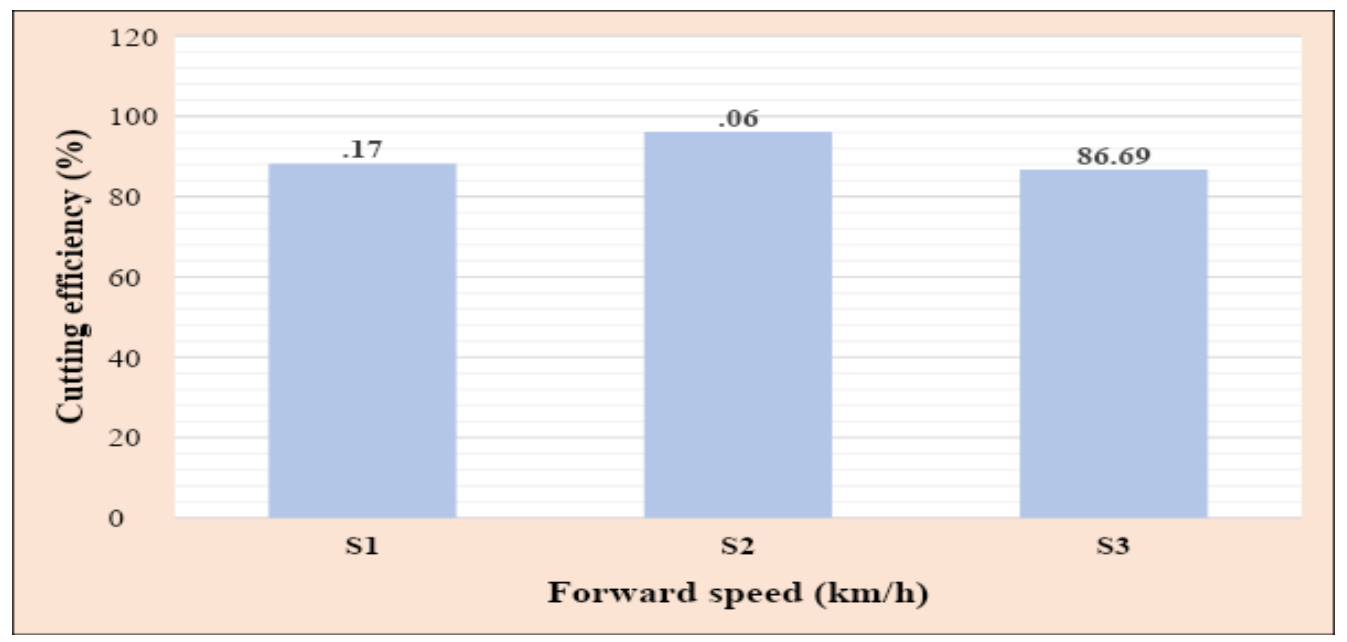


Fig.3 Effect of forward speed of machine on field efficiency (\%)

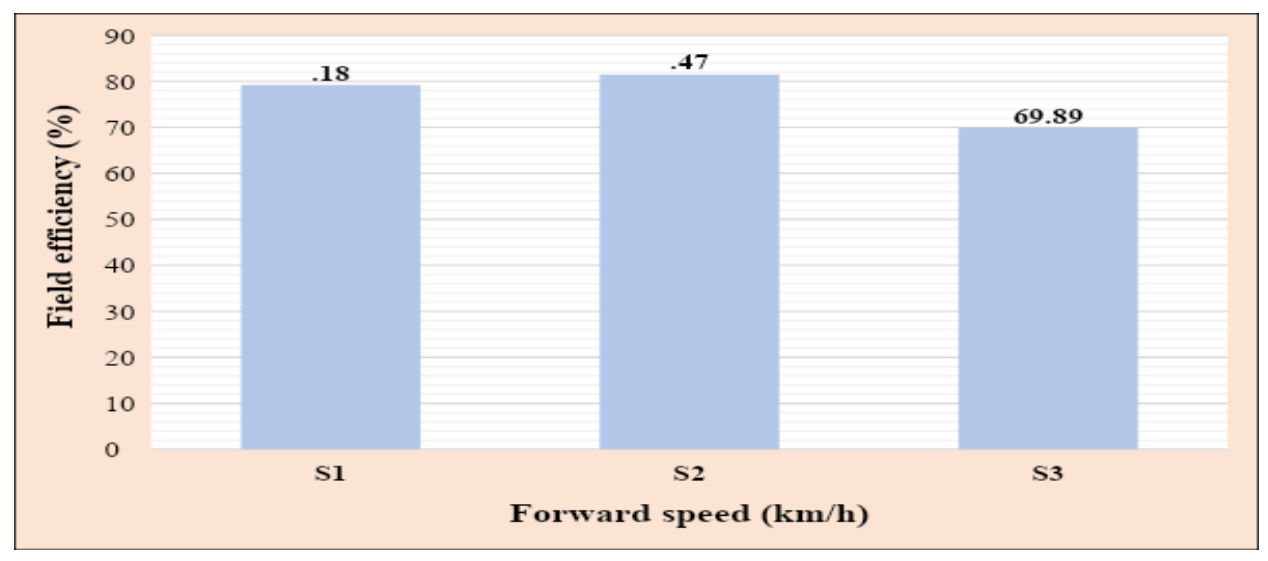

Fig.4 Effect of forward speed of machine on plant damage

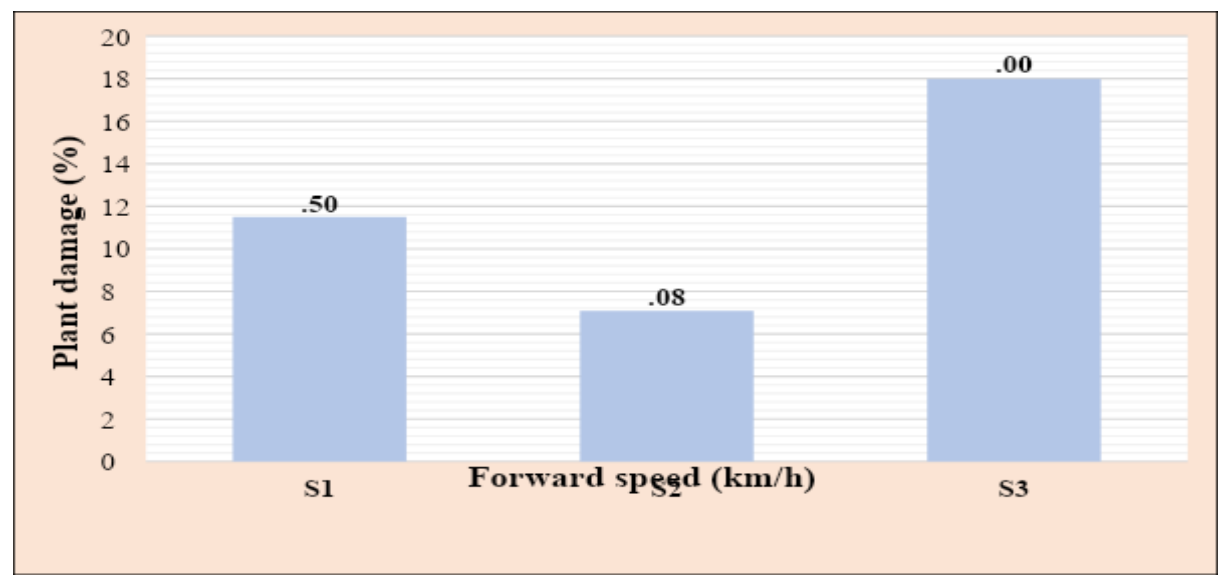

\section{Field efficiency}

Effect of the forward speed on field efficiency was found highly significant at $5 \%$ and $1 \%$ level (Table 2). The maximum field efficiency i.e. $81.47 \%$ was recorded with $\mathrm{S}_{2}$ forward speed. The minimum field efficiency i.e. 69.89 $\%$ was observed with $\mathrm{S}_{3}$ forward speed, while at $\mathrm{S}_{1}$ forward speed it was observed $79.18 \%$.

The field efficiency was plotted against forward speed of machine as shown in Fig. 3. From figure it is clear that the field efficiency increased as forward speed increased from $S_{1}$ to $S_{2}$. But it decreased with the further increased of speed i.e. from $S_{2}$ to $S_{3}$. At first instance, the field efficiency increased $16.56 \%$ as speed increased from $S_{1}(0.3-0.6 \mathrm{~km} / \mathrm{h})$ to $S_{2}(0.6-$
$0.9 \mathrm{~km} / \mathrm{h}$ ). However, further increased in speed from $S_{2}$ to $S_{3}$, the field efficiency decreased $14.21 \%$ as compared to $S_{2}$.

\section{Plant damage}

Effect of different forward speed on plant damage was found highly significant at $5 \%$ and $1 \%$ level (Table 3). The minimum plant damage $(7.08 \%)$ and maximum plant damage $(18.00 \%)$ were observed at forward speed $\mathbf{S}_{2}$ and $S_{3}$ respectively, while at $S_{1}$ forward speed it was found $11.49 \%$.

The plant damage is plotted against forward speed of machine as shown in Fig. 4. From Figure it is clear that, the minimum plant damage i.e. $7.08 \%$ was observed in the range of 
the forward speed of $0.6-0.9 \mathrm{~km} / \mathrm{h}$ i.e. $\mathrm{S}_{2}$ as compared to other speeds, while maximum plant damage was found at higher speed range of $0.9-1.2 \mathrm{~km} / \mathrm{h}$ i.e. $\mathrm{S}_{3}$. The reason of this might be due to at lowest speed not cut completely and fall down in front of the machine and get damaged. While in case of highest speed plant get down before cutting and get crushed due to machine sections. Thus, for minimum plant damage $S_{2}$ speed is recommended.

\section{Economics}

The operation cost was determined and analysed for the developed fodder crop harvester. Depreciation cost was calculated on the basis of straight-line method. Cost of the manual harvesting was found $\square 5400$ per ha, while the operating cost of the developed fodder crop harvester was found $\square 2515$ per ha. Thus, the total cost saving by the developed fodder crop harvester was found $58.07 \%$ as compare to manual harvesting (Table 4). Considering the custom hiring cost as $25 \%$ more than the total operation cost, it was found $\square 138.76$ per $h$. Average net annual benefit of machine was 9990.9. The payback period of machine was found 4 years. Benefit cost ratio of the machine was found 2.49 .

In conclusion

The developed machine gave its best performance at forward speed of $0.6-0.9$ $\mathrm{km} / \mathrm{h}$.

The cutting efficiency, field efficiency and plant damage of the developed machine were found $96 \%, 81 \%$ and $8 \%$ respectively.

The developed harvester could harvest one hectare in 22 hours while by manually harvesting it required 138 hours.

The cost of operation for harvesting fodder maize was found $\square 2515$ per ha while by manually harvesting it costed $\square 5400$ per ha.

The developed machine could reduce $58.07 \%$ cost of operation.

\section{References}

Alandkar, N. 2017. Development and performance evaluation of sorghum stalk cutter. M.Tech. (FMPE) Thesis (Unpublished). Vasantrao Naik Marathwada Krishi Vidyapeeth, Parbhani.

Amer Eissa, A. H. and Yadav, M. P. 2008. Fabrication and performance test of an ultraportable crop cutter. International Journal of Science Engineering and Research, 2(2): 13-25.

Hoseinzadeh, B., Esehaghbeygi, A. and Raghami, N. 2009. Effect of moisture content, bevel angle and cutting speed on shearing energy of three wheat varieties, World Applied Sciences Journal, 7(9): 11201123.

Kongre, U. V., Shahare, L., Mutkule, A. and Komawar, A. 2016. Fabrication of multicrop cutter. International Journal of Advanced Research in Science, Engineering and Technology, 3(4): 1878-1883.

Michael, A. M. and Ojha, T. P. 1978. Principles of Agricultural Engineering. Jain Brothers, New Delhi. pp. 63-72.

Yiljep, Y. and Mohammad, U. 2005. Effect of knife velocity on cutting energy and efficiency during impact cutting of sorghum stalk. Agricultural Engineering International: the CIGR E Journal, 7(4): 110.

\section{How to cite this article:}

Jalu, M. V., V. K. Tiwari and Vala, V. S. 2020. Development of Manually Drawn Engine Powered Fodder Crop Harvester. Int.J.Curr.Microbiol.App.Sci. 9(10): 2126-2132. doi: https://doi.org/10.20546/ijcmas.2020.910.259 